\title{
Introduction: Menstruation as Material
}

\author{
Katie Ann Hasson
}

The varying meanings attached to menstruation, the stories we tell about it, the ways we manage it, and even how we experience menstruation differ depending on time, place, culture, and individual embodiment. But menstruation itself should seem self-evident. Menstruation is a biological reality, after all-a material fact, a fluid produced by the body that can be seen and felt, a reality that gives rise to a range of materials and products designed to absorb or contain it. And yet, as the chapters in this section show, despite its seemingly obvious materiality, menstruation must nonetheless be made to "matter."

The material production surrounding menstruation includes a variety of menstrual management technologies such as pads, tampons, cups, and newer product innovations, such as the more than 100 cycle-tracking phone applications on the current market, "period-friendly" underwear, and subscription services that send consumers boxes of menstruation supplies on a monthly basis. It also includes a growing number of artistic productions, from Judy Chicago's work of the 1970s, including the lithograph "Red Flag" and the installation "Menstruation Bathroom," through more contemporary menstrual art shows, films, documentaries, and aesthetic objects—each of which shed light upon the social, political, and medical meanings of menstruation.

This section starts and ends with one of the most obvious manifestations of menstruation as material: menstrual management technologies. As Elizabeth Kissling asserts, "Within the current cultural logic of late capitalism, a woman's relationship to her menstrual cycle is largely defined through consumer products" $(2006,123)$. It begins with examinations of the material of these products themselves - what should a tampon or pad be made of, and how do scientists determine what is safe?-and closes with an examination of the economic interests engaged with producing and distributing these products. 
A number of chapters explore different ways of translating the materiality of menstruation into the languages of science, technology, and data. Science is one arena that has attempted to reckon with menstrual material in numerous, often problematic ways. The development and testing of tampons is one of these (where the outcomes are sometimes quite humorous: tiny mouse tampons! that ubiquitous blue fluid!). How can the messy materiality of menstruation as embedded in the bodies, lives, and experiences of menstruators be reconciled with demands for precise, objective data in the lab? This is particularly tricky when health and safety are at issue and experiments attempt to analyze tampon ingredients and absorption apart from the messy menstrual environment - that is, menstruators' bodies, which must be "instrumentalized," or turned into tools for scientific research. Vostral and Reame variously explore these questions in the case of tampon development and safety, raising questions and offering cautionary advice for today's menstrual health advocates.

Measuring and monitoring menstruation turns out to be complicated in a number of ways as well. From Reame's problematizing the use of saline solution to test tampon absorption, the chapters shift to other difficulties with measurement. What aspects of the menstrual cycle ought to be measured and how? Measuring and tracking hormone levels, menstruation-related school absences, and the length and characteristics of individual menstrual cycles all turn out to be less straightforward than one might presume. Measurements of hormone levels must be timed and matched by day of the menstrual cycle (Houghton and Elhadad); school absences are difficult to reliably track (Benshaul-Tolonen et al.); and period-tracking apps in their current form rely on a range of assumptions about gender, sexuality, behavior, and menstrual cycles that reduce their usefulness for a wide range of users (Fox and Epstein).

Several chapters examine the experience of menstruation in relation to its most concrete materiality. Steward et al. provide insights into both bodily sensations and menstrual management tasks and how they affect people with sensory and cognitive disabilities. My own research (in Chapter 58) examines the mismatches between experiences of monthly bleeding and definitions of menstruation that are changing to accommodate menstrual management technologies that aim to reshape the biology of menstruation using ingested hormones.

Artistic production has also proven fertile ground for exploring menstrual matters. The very substance of menstruation can be translated into the symbolic language of artistic representation and performance. How is blood portrayed in painting? How does this differ when that blood is "gendered," as in menstruation and childbirth? Cole explores the changing meanings and 
portrayals of gendered blood in art. Relatedly, in a series curated by Jen Lewis that pairs several artists' statements with examples of their work, we engage the process and product of creating art using menstrual materials-whether as medium or subject or both.

The last few chapters return to a discussion of menstrual technologies, particularly the multi-billion dollar industry that produces, markets, and sells menstrual management products around the world. Tarzibachi examines how Latin American countries are targeted as markets for menstrual products originating in the US, as well as how the meanings and use of these products in the Latin American context have changed over time. Punzi and Werner explore how social enterprises combine a social mission with a for-profit model to address the social problems surrounding menstruation, while investigating some of the challenges and critiques these hybrid ventures face. The final chapter engages representatives of a range of these "caring corporations" through a discussion of the tension between making a profit and promoting social change. Together, these concluding chapters provide a glimpse of how a new generation of companies are attempting to foster new relationships between women and girls and their bodies, and between wealthy consumers in the Global North and beneficiaries of free or reduced-cost products in lowand middle-income countries.

From high technology to classical art, scientific research to menstrual health education, the chapters in "Menstruation as Material" use a critical lens to explore the many manifestations of, sometimes quite literally, menstrual matters. This wide range of explorations necessitates a variety of approaches, and therefore the chapters in this section take many forms. Alongside social science and humanities pieces (drawing on a range of qualitative and quantitative research and analysis), we find personal reflections woven into a historical account of research on Toxic Shock Syndrome (TSS); artists' notes and narratives; and firsthand accounts of building businesses that aim not only to address the menstrual needs of individual consumers but also to foster tangible social transformation. Considered together, the contents of this section represent some of the ways that the field of critical menstruation studies simultaneously grapples with the materiality of - and the process of materializing-menstruation.

In the end, what remains clear is how little is actually self-evident after all.

\section{REFERENCES}

Kissling, Elizabeth. 2006. Capitalizing on the Curse: The Business of Menstruation. Boulder: Rienner. 
Open Access This chapter is licensed under the terms of the Creative Commons Attribution 4.0 International License (http://creativecommons.org/licenses/ by $/ 4.0 /)$, which permits use, sharing, adaptation, distribution and reproduction in any medium or format, as long as you give appropriate credit to the original author(s) and the source, provide a link to the Creative Commons license and indicate if changes were made.

The images or other third party material in this chapter are included in the chapter's Creative Commons license, unless indicated otherwise in a credit line to the material. If material is not included in the chapter's Creative Commons license and your intended use is not permitted by statutory regulation or exceeds the permitted use, you will need to obtain permission directly from the copyright holder. 